\title{
CORRELATION BETWEEN SHEET CARRIER DENSITY-MOBILITY PRODUCT AND PERSISTENT PHOTOCONDUCTIVITY IN ALGAN/GAN MODULATION DOPED HETEROSTRUCTURES
}

\author{
J. Z. Li, J. Li, J. Y. Lin, and H. X. Jiang \\ Department of Physics, Kansas State University \\ Manhattan, KS 66506-2601
}

\section{ABSTRACT}

High quality $\mathrm{Al}_{0.25} \mathrm{Ga}_{0.75} \mathrm{~N} / \mathrm{GaN}$ modulation-doped heterojunction field-effect transistor (MOD-HFET) structures grown on sapphire substrates with high sheet carrier density and mobility products $\left(n_{s} \mu>10^{16} / \mathrm{Vs}\right.$ at room temperature) have been grown by metal organic chemical vapor deposition (MOCVD). The optimized structures were achieved by varying structural parameters, including the AlGaN spacer layer thickness, the Si-doped AlGaN barrier layer thickness, the Si-doping concentration, and the growth pressure. In these structures, the persistent photoconductivity (PPC) effect associated with the two-dimensional electron gas (2DEG) system was invariantly observed. As a consequence, the characteristic parameters of the 2DEG were sensitive to light and the sensitivity was associated with permanent photoinduced increases in the 2DEG carrier mobility $(\mu)$ and sheet carrier density $\left(n_{s}\right)$. However, we observed that the magnitude of the PPC and hence the photoinduced instability associated with these heterostructures were a strong function of only one parameter, the product of $n_{s}$ and $\mu$, which is the most important parameter for the HFET device design. For a fixed excitation photon dose, the ratio of the low temperature PPC to the dark conductivity level was observed to decrease from $200 \%$ to $3 \%$ as the $n_{s} \mu(300 \mathrm{~K})$ product was increased from $0.048 \times 10^{16} / \mathrm{Vs}$ to $1.4 \times 10^{16} / \mathrm{Vs}$. Based on our studies, we suggest that the magnitude of the low temperature PPC can be used as a sensitive probe for monitoring the electronic quality of the AlGaN/GaN HFET structures.

\section{INTRODUCTION}

Recent progresses in III-nitride material growth and device processing have greatly extended their applications in the area of electronic as well as optoelectronic devices [1,2]. For electronic device applications, $\mathrm{Al}_{\mathrm{x}} \mathrm{Ga}_{1-\mathrm{x}} \mathrm{N} / \mathrm{GaN}$ heterojunction field-effect transistors (HFETs) have shown great promises in microwave and millimeter-wave electronic device applications [3-5]. However, the performance of AlGaN/GaN HFETs still falls far from that of the theoretical prediction [6]. Further improvements in $\mathrm{AlGaN} / \mathrm{GaN}$ heterojunction material quality as well as in structural design are needed. Routine but powerful material and device characterization methods must be established.

In this work, $\mathrm{Al}_{0.25} \mathrm{Ga}_{0.75} \mathrm{~N} / \mathrm{GaN}$ modulation-doped heterojunction field-effect transistor (MOD-HFET) structures grown on sapphire substrates have been produced by our metal organic chemical vapor deposition (MOCVD) system and characterized by Hall and persistent photoconductivity measurements. The persistent photoconductivity (PPC) effect, which has been observed previously in $\mathrm{GaN}$ materials by several groups [711], was universally presented in these $\mathrm{AlGaN} / \mathrm{GaN}$ HFET structures, indicating the presence of charge trapping effects. However, the magnitude of the PPC was observed to 
be a strong function of only one parameter, the product of sheet carrier density $\left(n_{s}\right)$ and the two-dimensional electron gas mobility $(\mu)$. Since $n_{s} \mu$ is the most important intrinsic material parameter for the HFET structural design, the magnitude of PPC in turn can be utilized as a sensitive probe for monitoring the electronic qualities of the AlGaN/GaN MOD-HFET structures.

\section{EXPERIMENTAL DETAILS}

The inset of Fig. 1 is a schematic diagram showing the generic structure of samples used in this work which consisted of a $1.3 \mu \mathrm{m}$ highly insulating $\mathrm{GaN}$ epilayer followed by an $\mathrm{Al}_{0.25} \mathrm{Ga}_{0.75} \mathrm{~N}$ spacer layer and finally a Si-doped $\mathrm{Al}_{0.25} \mathrm{Ga}_{0.75} \mathrm{~N}$ layer. The structures were deposited over basal plane sapphire substrates using a variable pressure MOCVD system at a growth temperature of $1050{ }^{\circ} \mathrm{C}$. A total of seven samples with varying growth or structural parameters were studied. For the PPC measurements, a 1.5 $\mathrm{V}$ bias was supplied to the sample, a Hg lamp was used as an excitation source, and the conductivity was monitored through current $\left(I_{p p c}\right)$ by using an electrometer. To ensure that each set of data obtained under different temperatures have the same initial conditions, the system was always heated up to $300 \mathrm{~K}$, then cooled down in darkness to the desired measurement temperatures. The excitation intensity and buildup time span are fixed for different temperatures and samples. Fig. 1 illustrates the temperature variations of the sheet carrier density and mobility for one of our optimized structures. The values of the sheet carrier density and mobility products $\left(n_{s} \mu\right)$ at different temperatures shown in Fig. 1 are among those highest values reported for the $\mathrm{AlGaN} / \mathrm{GaN}$ HFET structures grown on sapphire substrates [12-14].

For all seven structures investigated here, the conductivity of the 2DEG channel is enhanced after exposure to light. Moreover, the light enhanced conductivity persists for a

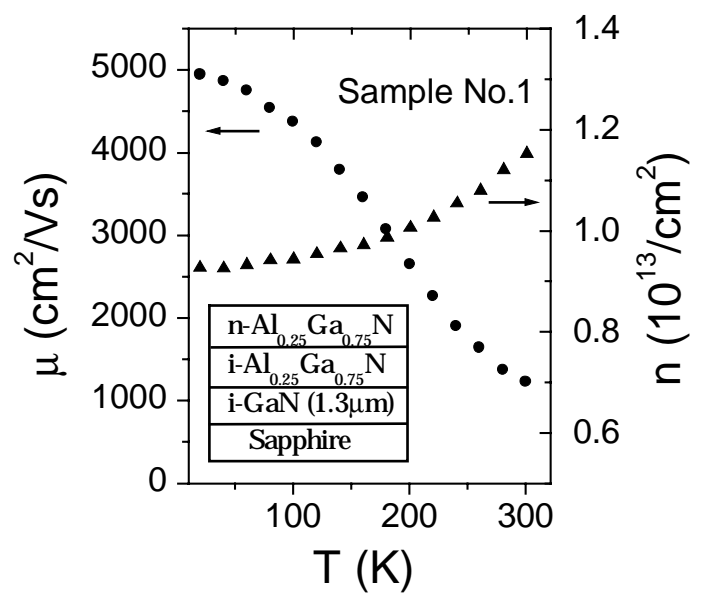

Fig. 1 2DEG sheet carrier density $\left(n_{s}\right)$ and mobility $(\mu)$ versus temperature, T, measured in a dark state for one of our optimized $\mathrm{Al}_{0.2} \mathrm{Ga}_{0.8} \mathrm{~N} / \mathrm{GaN}$ MOD-HFET structures. The inset shows the generic structures for the samples used in this study. 


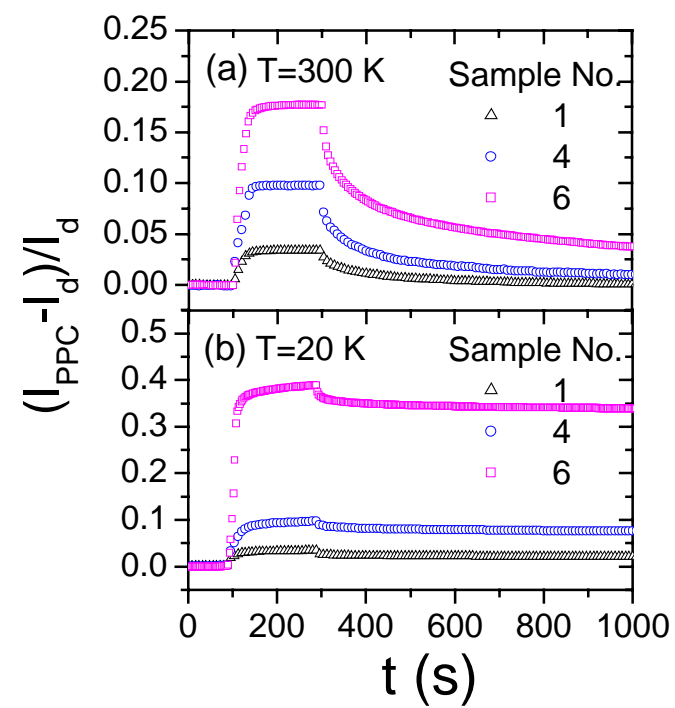

Fig. 2 Buildup and decay kinetics of PPC associated with the 2DEG system in three $\mathrm{Al}_{0.25} \mathrm{Ga}_{0.75} \mathrm{~N} / \mathrm{GaN}$ MOD-HFET structures measured at two representative temperatures, (a) $\mathrm{T}=300 \mathrm{~K}$ and (b) $\mathrm{T}=20 \mathrm{~K}$. Here $I_{\mathrm{ppc}}$ denotes the persistent photocurrent measured at time $\mathrm{t}$ and $I_{\mathrm{d}}$ the initial dark current levels.

long period of time after the removal of excitation source, an effect which is referred to as PPC. In Fig. 2, we present the PPC results obtained for three representative samples measured at two different temperatures. We can see that the decay time constants of the low temperature PPC are very long. By formulating the PPC buildup and decay kinetics in an $\mathrm{AlGaN} / \mathrm{GaN}$ heterostructure, we have previously attributed the PPC effect to the photoionization of deep level centers in $\mathrm{AlGaN}$ barrier [11]. It is well known from the earlier works on the AlGaAs/GaAs MODFETs that the PPC effects are detrimental to their performance [15]. The effects include sensitivity to light, a shift of the threshold voltage, and collapse of the drain I-V characteristics, all of which reduced the usefulness of the $\mathrm{AlGaAs} / \mathrm{GaAs}$ MODFET for integrated circuits. Interestingly, for $\mathrm{AlGaN} / \mathrm{GaN}$ HFET structures studied here, we observe that the magnitude of PPC and hence the device instabilities can be minimized by varying the growth conditions as well as structural parameters. Table 1 summarizes our Hall and PPC measurement results for all seven structures with different structural and growth parameters. As shown in Table 1, the magnitude of PPC or the photoinduced conductivity enhancement $\left(I_{p p c}-I_{d}\right)$ over its dark level $\left(I_{d}\right)$ is about $200 \%$ in sample \#7, but is negligibly small (only about $3 \%$ ) in sample \#1.

The general trends shown in Table 1 are that samples possess higher mobilities as well as higher sheet carrier densities exhibit reduced PPC, however, with a few exceptions (e.g., samples \#4 \& \#5). By carefully inspecting the results summarized in Table 1 , we can clearly see that the magnitude of PPC has a systematic dependence only 
on the product of the 2DEG sheet carrier density and mobility, i.e., $n_{s} \mu$, the most important intrinsic material parameter for the HFET device design. In Fig. 3, we have replotted the the magnitude of PPC versus $n_{s} \mu$ measured at $20 \mathrm{~K}$ (a) and $300 \mathrm{~K}$ (b). At both temperatures, the magnitude of PPC decreases monotonously with an increase of $n_{s} \mu$, follows the relationship of

$$
R_{p p c}=\mathrm{A}\left(n_{s} \mu\right)^{-\alpha} \text {. }
$$

Here the magnitude of PPC $\left(R_{p p c}\right)$ is defined as $\left[\left(I_{p p c}-I_{d}\right) / I_{d}\right]$ and A and $\alpha$ are two constants. As illustrated in Table 1, the better structures (i.e., larger values of $n_{s} \mu$ ) were achieved by varying (i) the AlGaN space layer thickness, (ii) the Si-doped AlGaN layer thickness, (iii) the doping levels in the Si-doped AlGaN layer, and (iv) the growth pressure. The electronic qualities (or $n_{s} \mu$ values) of these HFET structures can be further improved slightly by adjusting the four parameters described above until the magnitude of PPC further reduces to zero. However, we speculate that further dramatic enhancements in $\mathrm{AlGaN} / \mathrm{GaN}$ heterostructure material quality require further enhancements in epitaxial film qualities of both the underlying i-GaN and the top AlGaN epilayers.

Table 1. Hall-effect and PPC measurement results of the seven $\mathrm{Al}_{0.25} \mathrm{Ga}_{0.75} \mathrm{~N} / \mathrm{GaN}$ MODHFET structures obtained at $20 \mathrm{~K}$ and $300 \mathrm{~K}$, together with the structural parameters (spacer and Si-doped $\mathrm{AlGaN}$ layer thicknesses), the relative Si-doping levels $\left(\mathrm{SiH}_{4}\right.$ flow rate), and the growth pressure. All structures were grown at $1050{ }^{\circ} \mathrm{C}$ in a variable pressure MOCVD. Here $I_{p p c}$ denotes the buildup levels of the persistent currents for a fixed excitation intensity and buildup time span and $I_{d}$ the initial dark current levels.

\begin{tabular}{|c|c|c|c|c|c|c|c|}
\hline $\begin{array}{c}\text { Sample } \\
\text { No. }\end{array}$ & $\begin{array}{c}\mu \\
\left(\mathrm{cm}^{2} / V s\right) \\
20 \mathrm{~K} / 300 \mathrm{~K}\end{array}$ & $\begin{array}{c}n_{s} \\
\left(10^{13} / \mathrm{cm}^{2}\right) \\
20 \mathrm{~K} / 300 \mathrm{~K}\end{array}$ & $\begin{array}{c}n_{s} \mu \\
\left(10^{I 6} / V s\right) \\
20 \mathrm{~K} / 300 \mathrm{~K}\end{array}$ & $\begin{array}{c}\text { PPC ratio } \\
{\left[\left(I_{P P C}-I_{d}\right) / I_{d}\right] \times 100 \%} \\
20 \mathrm{~K} / 300 \mathrm{~K}\end{array}$ & $\begin{array}{c}\text { i-AlGaN/n-GaN } \\
\text { Thickness } \\
\text { (nm) }\end{array}$ & $\begin{array}{c}\mathrm{SiH}_{4} \\
(\mathrm{sccm})\end{array}$ & $\begin{array}{c}\text { Pressure } \\
\text { (torr) }\end{array}$ \\
\hline 1 & $4950 / 1230$ & $0.93 / 1.15$ & $4.95 / 1.42$ & $3.31 / 3.42$ & $6 / 25$ & 3 & 100 \\
\hline 2 & $3760 / 870$ & $0.76 / 1.37$ & $2.86 / 1.19$ & $5.84 / 5.32$ & $8 / 25$ & 1 & 150 \\
\hline 3 & $2920 / 884$ & $0.78 / 1.13$ & $2.28 / 1.00$ & $7.10 / 6.75$ & $4 / 25$ & 1 & 150 \\
\hline 4 & $2150 / 573$ & $0.84 / 0.92$ & $1.81 / 0.53$ & $8.34 / 11.15$ & $6 / 25$ & 1 & 150 \\
\hline 5 & $1620 / 703$ & $0.69 / 0.74$ & $1.13 / 0.52$ & $37.35 / 14.34$ & $6 / 25$ & 1 & 100 \\
\hline 6 & $600 / 280$ & $0.99 / 1.16$ & $0.59 / 0.33$ & $39.18 / 18.27$ & $6 / 25$ & 5 & 100 \\
\hline 7 & $2800 / 485$ & $0.11 / 0.09$ & $0.31 / 0.048$ & $200.35 / 300.24$ & $25 / 25$ & 0 & 77 \\
\hline
\end{tabular}

The strong PPC effect observed in several samples here is associated with both the photoinduced increases in 2DEG sheet carrier density and mobility. In these structures, the sheet carrier densities at fixed temperatures in a single sample can be continuously varied by varying the excitation photon dose, while the increases in sheet carrier densities also result in enhancements in 2DEG mobilities. Such behaviors have been seen previously in an AlGaN/GaN HFET structure [11], which clearly demonstrates that one of the possible ways to enhance the 2DEG mobilities is to increase the sheet carrier densities in the 2DEG channel region. In desired structures with minimal PPC effects, enhanced mobilities can be accomplished by barrier or channel doping. However, at much greater sheet carrier densities, the population of the higher-lying subbands could limit the overall mobility of the structure due to intersubband scattering as well as the 


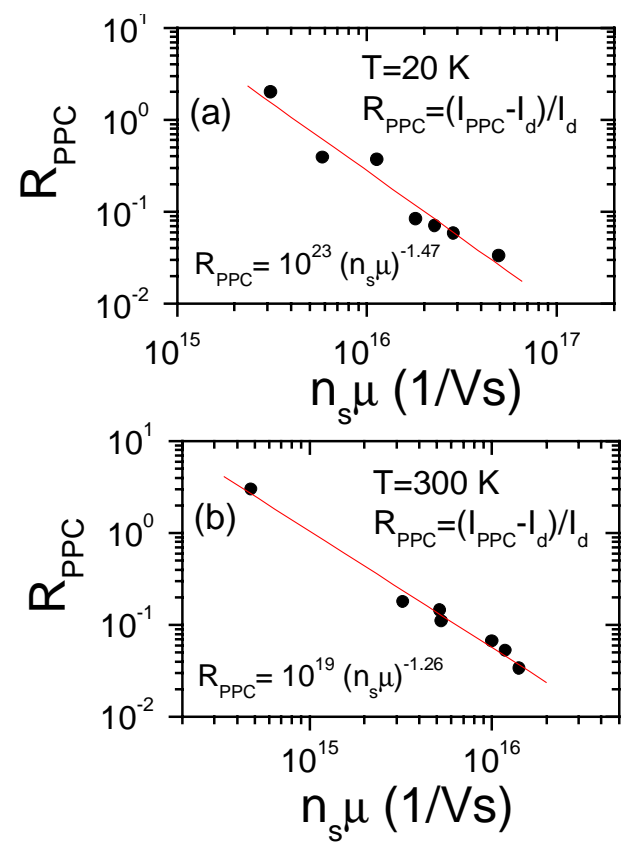

Fig. 3 The magnitude of PPC, $R_{p p c}$, or the photoinduced conductivity enhancement for a fixed excitation intensity and buildup time span $\left(I_{p p c}-I_{d}\right)$ over its dark level $\left(I_{d}\right)$ as a function of the product of the sheet carrier density and mobility, $n_{s} \mu$, obtained from seven different HFET structures. The solid lines are the least squares fits to experimental data with $R_{p p c}=\mathrm{A}\left(n_{s} \mu\right)^{-\alpha}$. The fitted values of $\alpha(\mathrm{A})$ are $1.47\left(10^{23}\right)$ and $1.26\left(10^{19}\right)$ at $20 \mathrm{~K}$ and $300 \mathrm{~K}$, respectively.

loss of the true two-dimensional behavior due to a virtual continuum of bands being populated $[12,16,17]$. Thus a trade-off between these effects must be considered.

In summary, we have shown in this work that the most important intrinsic material parameter for the AlGaN/GaN HFET device design, namely the sheet carrier and mobility product $\left(n_{s} \mu\right)$ is strongly correlated with the magnitude of PPC in these structures. As a result, the magnitude of PPC can be utilized as a sensitive probe for monitoring the electronic qualities of the AlGaN/GaN MOD-HFET structures. We observed that the magnitude of the PPC and hence the photoinduced instability associated with these heterostructures decreases rapidly with an increase of $n_{s} \mu$, according to $\mathrm{R}_{\mathrm{ppc}} \propto\left(n_{s} \mu\right)^{-\alpha}$, with $\alpha$ varying from 1.26 to 1.47 in the temperature range of 20 to $300 \mathrm{~K}$.

\section{ACKNOLEGEMENTS}

This research is supported by BMDO (Dr. Kepi Wu) monitored by USASSDC, NSF (DMR-99502431), and DOE(DE-FG03-96ER45604). 


\section{REFERENCES:}

1. H. Morkoc, S. Strite, G. B. Gao, M. E. Lin, B. Sverdlov, and M. Burns, J.Appl.Phys.76, 1363 (1994).

2. S. N. Mohammad, A. A. Salvador, and H. Morkoc, Proc. IEEE 83, 1306 (1995).

3. M. A. Khan, M. S. Shur, J. N. Kuznia, Q. Chen, J. Burn, and W. Schaff, Appl. Phys. Lett. 66, 1083 (1994).

4. L. Eastman, K. Chu, W. Schaff, M. Murphy, N. G. Weimann, and T. Eustis, MRS internet J. Nitride Semicond. Res. 2, 17, (1997).

5. Y. F. Wu, B. P. Keller, P. Fini, S. Keller, T. J. Jenkins, L. T. Kehias, and S. P. DenBaars, IEEE Electron. Device Lett. 19, 50 (1998).

6. B. Gelmont, K. S. Kim, and M. Shur, J. Appl. Phys. 74, 1818 (1993).

7. C. Johnson, J. Y. Lin, H. X. Jiang, M. Asif Khan, and C. J. Sun, Appl. Phys. Lett. 68, 1808 (1996).

8. G. Beadie, W. S. Rabinovich, A. E. Wickenden, D. D. Koleske, S. C. Binari, and J. A. Freitsa, Jr., Appl. Phys. Lett. 71, 1092 (1997).

9. C. H. Qiu and J. I. Pankove, Appl. Phys. Lett. 70, 1983 (1997).

10. M. T. Hirsch, A. Wolk, W. Walukiewicz, and E. E. Haller, Appl. Phys. Lett. 71, 1098 (1997).

11. J. Z. Li, J. Y. Lin, H. X. Jiang, M. Asif Khan, and Q. Chen, J. Appl. Phys. 82, 1227 (1997). J. Vac. Sci. Technol. B15, 1117 (1997).

12. R. Gaska, M. S. Shur, A. D. Bykhovski, A. O. Orlov, and G. L. Snider, Appl. Phys. Lett. 74, 287 (1999).

13. T. Wang, Y. Ohno, M. Lachab, D. Nakagawa, T. Shirahama, S. Sakai, and H. Ohno, Appl. Phys. Lett. 74, 3531 (1999).

14. C. R. Elsass, I. P. Smorchkova, B. Heying, E. Haus, P. Fini, K. Maranowski, J. P. Ibbetson, S. Keller, P. M. Petroff, S. P. DenBaars, U. K. Mishra, and J. S. Speck, Appl. Phys. Lett. 74, 3528 (1999).

15. P. M. Mooney, J. Appl. Phys. 67 R1 (1990).

16. X. Z. Dang, P. M. Asbeck, E. T. Yu, G. J. Sullivan, M. Y. Chen, B. T. McDermott, K. S. Bouttros, and J. M. Redwing, Appl. Phys. Lett. 74, 3890 (1999).

17. L. Hsu and W. Walukiewicz, Phys. Rev. B56, 1520 (1999). 